\title{
NÍVEL CRÍTICO DE FÓSFORO NO SOLO PARA PANICUM MAXIMUM JACQ. CV. TANZÂNIA ${ }^{1}$
}

\author{
EMERSON DE OLIVEIRA GHERI², MARA CRISTINA PESSÔA DA CRUZ ${ }^{3}$, \\ MANOEL EVARISTO FERREIRA ${ }^{4}$ e LEONARDO ANDRÉ SCHIAVETO DA PALMA ${ }^{5}$
}

\begin{abstract}
RESUMO - Foram avaliados os efeitos da aplicação de fósforo $(\mathrm{P})$ em solo argiloso, de textura média e arenoso, sobre a produção de matéria seca de Panicum maximum Jacq. cv. Tanzânia. O ensaio foi conduzido em casa de vegetação, em vasos de plástico contendo $10 \mathrm{dm}^{3}$ de solo, em esquema fatorial e delineamento inteiramente ao acaso. Após calagem para $V=70 \%$ e aplicação de $0,35,70,105$ e $140 \mathrm{mg} / \mathrm{dm}^{3}$ de $\mathrm{P}$, o solo foi umedecido, e depois de 30 dias, secado e amostrado. O ensaio foi conduzido por 76 dias, a partir da emergência das plântulas, com o primeiro corte aos 48 dias, a $10 \mathrm{~cm}$ do solo, e o segundo, aos 76, rente ao solo. Com a aplicação de $\mathrm{P}$ houve aumento de produção de matéria seca, e o maior acréscimo ocorreu com a aplicação de $35 \mathrm{mg} / \mathrm{dm}^{3}$. A maior produção foi obtida no solo de textura média. $\mathrm{O}$ teor de $\mathrm{P}$ nas plantas estava adequado nos solos arenoso e argiloso. No de textura média, ele diminuiu com o aumento da produção, caracterizando efeito de diluição. Com a produção relativa e o teor de $\mathrm{P}$ de cada solo, foi determinado o nível crítico de $38 \mathrm{mg} / \mathrm{dm}^{3}$ de $\mathrm{P}$ extraído por resina.
\end{abstract}

Termos para indexação: gramíneas forrageiras, adubação, nutrientes, matéria seca, análise de solo, textura do solo.

CRITICAL LEVEL OF SOIL PHOSPHORUS TO PANICUM MAXIMUM CV. TANZÂNIA

\begin{abstract}
A greenhouse experiment was carried out to evaluate the effects of phosphorus (P) application on dry matter production of Panicum maximum Jacq. cv. Tanzânia. The experimental design was completely randomized, in outline complete factorial combining three soils with different textures (sandy, middle, clay) and five P levels: $0,35,70,105$ and $140 \mathrm{mg} / \mathrm{dm}^{3}$. After liming to elevate base saturation degree to $70 \%$ and $\mathrm{P}$ application, the soils were moistened and after 30 days they were dried and sampled. Plastic pots with $10 \mathrm{dm}^{3}$ soil were used and the grass grew for 76 days. In this period two cuts were made: the first one, at $10 \mathrm{~cm}$ above soil, 48 days after emergency, and the second, 76 days after the first one, at the soil surface. The dry matter production increased with $\mathrm{P}$ application for the three soils and the maximum increase was observed with $35 \mathrm{mg} / \mathrm{dm}^{3}$ application. The maximum production was obtained with middle texture soil. The P content was normal in the sandy and clayish soils, but in the middle texture soils it decreased with the production increase, showing a dilution effect. With the relative production and the $\mathrm{P}$ content of each soil, the critical level of $\mathrm{P}$ extracted by means of resin was $38 \mathrm{mg} / \mathrm{dm}^{3}$.
\end{abstract}

Index terms: feed grasses, fertilizer application, nutrients, dry matter, soil testing, soil texture.

\footnotetext{
${ }^{1}$ Aceito para publicação em 27 de dezembro de 1999.

Extraído do trabalho de graduação, apresentado pelo primeiro autor à Faculdade de Ciências Agrárias e Veterinárias (FCAV), Universidade Estadual Paulista (UNESP), Jaboticabal, SP.

${ }^{2}$ Zootec., Rua Miguel Ignácio, 153, CEP 14090-530 Ribeirão Preto, SP. Bolsista da FAPESP. E-mail: gheri@ coc.com.br
}

\footnotetext{
${ }^{3}$ Eng. Agrôn., Dr., Prof. Assistente, Dep. de Solos e Adubos, FCAV, UNESP, Via de Acesso Prof. Paulo Donato Castellane, s/n, CEP 14870-000 Jaboticabal, SP. Bolsista do CNPq. E-mail: mcpcruz@fcav.unesp.br

${ }^{4}$ Eng. Agrôn., Dr., Prof. Titular, Dep. de Solos e Adubos, FCAV, UNESP. E-mail: evaristo@fcav.unesp.br

${ }^{5}$ Graduando do Curso de Zootecnia, FCAV, UNESP.

E-mail: leonardospalma@zipmail.com.br
} 


\section{INTRODUÇÃO}

A pecuária no Brasil está buscando maior rendimento por meio de pastagens com forrageiras altamente produtivas, associadas a boas condições de fertilidade do solo e, às vezes, a irrigação.

De acordo com Euclides (1996), a forrageira mais utilizada na engorda de bovinos e uma das mais importantes em extensão de área cultivada foi o capimcolonião (Panicum maximum Jacq. cv. Colonião). Contudo, a sua pouca adaptabilidade a solos de baixa fertilidade e pouca resistência à seca fizeram com que fosse substituída por gramíneas menos produtivas e de pior qualidade, mas mais tolerantes a condições adversas. Segundo o autor, o interesse pela espécie Panicum maximum Jacq. voltou a aumentar recentemente em razão do lançamento das cultivares Tobiatã, Tanzânia, Vencedor, Centenário e Centauro.

A cultivar Tanzânia foi trazida da Tanzânia, África, e introduzida e lançada no Brasil pela EmbrapaCentro Nacional de Pesquisa de Gado de Corte. Apresenta boa aceitabilidade pelos animais, com ganhos de peso elevados e aumento relativo da taxa de lotação da pastagem. Possui altura média, boa produção de massa, e cobre bem o solo quando adubado e manejado de forma adequada (Vieira, 1993).

Em Campo Grande (MS), Euclides (1994) comparou as cultivares Colonião, Tobiatã e Tanzânia quanto à persistência sob pastejo, produção animal e capacidade de suporte. Ocorreu maior ganho de peso animal com os capins tanzânia e mombaça quando estavam no solo mais fértil, o que está de acordo com a maior exigência dessas plantas.

De maneira geral, as cultivares de Panicum maximum Jacq. apresentam alta resposta à adubação com P. Costa et al. (1983), em casa de vegetação, determinaram que a máxima produção de matéria seca ocorre com a aplicação de 240 a $250 \mathrm{mg} / \mathrm{kg}$ de P, e o máximo incremento de produção, com a dose $50 \mathrm{mg} / \mathrm{kg}$ de P. Também em vasos, Rego et al. (1985) observaram que com a aplicação de 200 ppm de P, 49,2\% do P aplicado permaneceu disponível no solo arenoso, e nos solos de textura argilosa e argilo-arenosa avaliados, apenas cerca de $12 \%$.

Com a cultivar Tanzânia, Sengik et al. (1996a) realizaram trabalho em casa de vegetação, em solo contendo $1 \mathrm{mg} / \mathrm{kg}$ de $\mathrm{P}$ e concluíram que a calagem diminuiu a produção. Quando usaram o mesmo solo em outro experimento (Sengik et al., 1996b) ficou demonstrado que a falta de resposta à calagem foi causada pela deficiência de $\mathrm{P}$, uma vez que o tratamento com calagem e o sem $\mathrm{P}$ apresentaram produções muito pequenas e semelhantes $(0,20$ e $0,24 \mathrm{~g} / \mathrm{vaso}$, respectivamente). Somente quando foi feita calagem mais adubação $\mathrm{N}, \mathrm{P}, \mathrm{K}$ e $\mathrm{S}$ é que o capim chegou à produção máxima ( $8,58 \mathrm{~g} / \mathrm{vaso})$.

Corrêa et al. (1996), avaliando quatro cultivares de Panicum maximum (Tanzânia, Mombaça, Vencedor e T21) e seis doses de $\mathrm{P}(0,50,100,200,400$ e $800 \mathrm{~kg} / \mathrm{ha}$ de $\mathrm{P}_{2} \mathrm{O}_{5}$ ) na forma de superfosfato triplo granulado, observaram que as quatro cultivares responderam igualmente à adubação fosfatada, aumentando de forma significativa a produção de matéria seca. Os teores de P na matéria seca aumentaram significativamente com as doses, e os níveis críticos no solo e na planta para atingir $80 \%$ da produção máxima foram $21 \mathrm{mg} / \mathrm{dm}^{3}$ de P e 2,3 g/kg de P, respectivamente. Posteriormente, Corrêa et al. (1997) testaram os efeitos de seis doses de $\mathrm{P}$ na parcela principal, e três fontes de P nas subparcelas, sobre a produção de capim-tanzânia. O capim respondeu ao $\mathrm{P}$ independentemente da fonte, e com doses maiores do que $200 \mathrm{~kg} / \mathrm{ha}$ não houve aumento significativo de produção.

Segundo a recomendação existente para o Estado de São Paulo (Werner et al., 1996), a calagem para o capim-tanzânia deve ser feita para elevar o índice de saturação por bases a $70 \%$ (formação da pastagem) ou $60 \%$ (manutenção), e a adubação fosfatada varia de 0 a $100 \mathrm{~kg} / \mathrm{ha}$ de $\mathrm{P}_{2} \mathrm{O}_{5}$, em razão do teor de $\mathrm{P}$ no solo. Tendo em vista seu lançamento recente, existem poucas informações sobre as condições de fertilidade do solo mais favoráveis ao cultivo, mas apesar disso, é considerada planta exigente.

O objetivo deste trabalho foi avaliar a resposta do capim-tanzânia, em vasos, à aplicação de P no solo, e determinar o nível crítico do nutriente no solo para esse capim.

\section{MATERIAL E MÉTODOS}

O ensaio foi realizado em casa de vegetação, empregando-se três solos com diferentes texturas (argilosa, média e arenosa), um Latossolo Roxo distrófico, um Latossolo 
Vermelho-Escuro textura média, e um Podzólico Vermelho-Amarelo, cinco doses de $\mathrm{P}$ e o capim-tanzânia (Panicum maximum Jacq. cv. Tanzânia). Foi utilizado esquema fatorial em delineamento inteiramente casualizado, com quatro repetições, totalizando 60 vasos.

Cada solo foi coletado na camada de 0 a $20 \mathrm{~cm}$, secado ao ar, destorroado, passado através de peneira de $6 \mathrm{~mm}$ de abertura de malha, homogeneizado e amostrado, para análise granulométrica (Camargo et al., 1986) e para avaliação da fertilidade (Raij et al., 1987). Os resultados estão apresentados respectivamente nas Tabelas 1 e 2 .

Com base na análise química, calculou-se a dose de $\mathrm{CaCO}_{3}$ e de $\mathrm{Mg}_{2}(\mathrm{OH})_{2} \mathrm{CO}_{3}$ para elevar o índice de saturação por bases de cada solo a $70 \%$, mantendo a relação $\mathrm{Ca}: \mathrm{Mg}$ de 4:1. Os corretivos foram misturados a $10,5 \mathrm{dm}^{3}$ de solo seco, sobre pedaço de plástico, juntamente com o fosfato monoamônico, aplicado de acordo com o tratamento, nas doses $0\left(\mathrm{P}_{0}\right), 35\left(\mathrm{P}_{1}\right), 70\left(\mathrm{P}_{2}\right), 105\left(\mathrm{P}_{3}\right)$ e $140\left(\mathrm{P}_{4}\right) \mathrm{mg} / \mathrm{dm}^{3}$ de $\mathrm{P}$, e a uréia, para ajustar a dose de $\mathrm{N}$ aplicada no tratamento $\mathrm{P}_{4}\left(63,23 \mathrm{mg} / \mathrm{dm}^{3}\right.$ de N). Após a mistura, o solo de cada tratamento foi transferido para vaso de plástico com capacidade para $12 \mathrm{~L}$ e, em seguida, umedecido a $60 \%$ da capacidade de retenção de água, empregando-se água desionizada. Foram aguardados 30 dias de incubação, ajustando-se periodicamente a umidade. $\mathrm{Na}$ metade desse período foi aplicada solução contendo $\mathrm{K}$, $\mathrm{S}$ e micronutrientes. $\mathrm{O} \mathrm{K}$ foi aplicado em dose neces-

TABELA 1. Análise granulométrica dos solos empregados no experimento ${ }^{1}$.

\begin{tabular}{|c|c|c|c|c|}
\hline \multirow[t]{2}{*}{ Solo } & \multirow[t]{2}{*}{ Argila } & \multirow[t]{2}{*}{ Silte } & \multicolumn{2}{|c|}{ Frações de areia } \\
\hline & & & Grossa & Fina \\
\hline & ------- & ---- $(g$ & 5) ---- & ---- \\
\hline Arenoso & 235 & 51 & 459 & 254 \\
\hline Textura média & 301 & 45 & 400 & 254 \\
\hline Argiloso & 634 & 244 & 27 & 96 \\
\hline
\end{tabular}

${ }^{1}$ Médias de duas repetições. sária para elevar o teor no solo em $3 \mathrm{mmol}_{\mathrm{c}} / \mathrm{dm}^{3}$, metade como $\mathrm{KCl}$ e metade como $\mathrm{K}_{2} \mathrm{SO}_{4}$, o que resultou na adição de $24 \mathrm{mg} / \mathrm{dm}^{3}$ de S. Os micronutrientes B, Cu, Mn, Mo e Zn foram aplicados nas doses 0,5, 1,25, 3,0, 0,02 e $2,5 \mathrm{mg} / \mathrm{dm}^{3}$, respectivamente, e as fontes utilizadas foram $\mathrm{H}_{3} \mathrm{BO}_{3}, \mathrm{CuSO}_{4} .5 \mathrm{H}_{2} \mathrm{O}, \mathrm{MnCl}_{2} .4 \mathrm{H}_{2} \mathrm{O}$, $\left(\mathrm{NH}_{4}\right)_{6} \mathrm{Mo}_{7} \mathrm{O}_{24} \cdot 4 \mathrm{H}_{2} \mathrm{O}$ e $\mathrm{ZnSO}_{4} .7 \mathrm{H}_{2} \mathrm{O}$.

Após a incubação, o solo de cada vaso foi secado sobre pedaço de plástico, destorroado, passado em peneira de $6 \mathrm{~mm}$ de abertura de malha, homogeneizado, e cerca de $0,5 \mathrm{dm}^{3}$ foi coletado para análises, devolvendo-se $10 \mathrm{dm}^{3}$ para cada vaso.

A semeadura do capim-tanzânia foi feita em 23/1/98, na profundidade aproximada de $1 \mathrm{~cm}$, e o solo foi reumedecido a $60 \%$ da capacidade de retenção de água. Depois de cinco dias, a maioria das plântulas havia emergido, e doze dias após a emergência foi realizado o desbaste, deixando-se quatro plantas por vaso.

A partir dos 15 dias após a emergência, foram feitas aplicações semanais de solução de nitrato de amônio e nitrato de potássio, totalizando $530 \mathrm{mg} / \mathrm{dm}^{3}$ de $\mathrm{N}$ e $390 \mathrm{mg} / \mathrm{dm}^{3}$ de $\mathrm{K}$ até o primeiro corte, que foi feito aos 48 dias após a emergência, a $10 \mathrm{~cm}$ da superfície do solo. O segundo corte, rente ao solo, aconteceu 76 dias após a emergência. No intervalo entre o primeiro e o segundo corte foram aplicados mais $368 \mathrm{mg} / \mathrm{dm}^{3}$ de $\mathrm{N}$ e $300 \mathrm{mg} / \mathrm{dm}^{3}$ de $\mathrm{K}$, além de $20 \mathrm{mg} / \mathrm{dm}^{3}$ de $\mathrm{S}$ como sulfato de amônio.

Ao final de cada período de crescimento, as plantas cortadas foram lavadas de acordo com descrito em Bataglia et al. (1983) e secadas em estufa a cerca de $65^{\circ} \mathrm{C}$ até peso constante. Após a secagem e a obtenção do peso da matéria seca produzida, as plantas foram moídas, e as amostras, submetidas a digestão nítrico-perclórica. Nos extratos foi feita determinação de $\mathrm{P}$ por colorimetria. Os dados de matéria seca, de teores de $\mathrm{P}$ e de quantidade de $\mathrm{P}$ absorvida foram submetidos a análise de variância pelo teste $\mathrm{F}$ e de regressão, e o nível crítico de $\mathrm{P}$ no solo foi determinado pelo método gráfico de Cate Junior \& Nelson (1965).

TABELA 2. Características químicas dos solos estudados, antes da incubação.

\begin{tabular}{|c|c|c|c|c|c|c|c|c|c|c|c|c|c|c|}
\hline Textura & $\begin{array}{c}\mathrm{P} \\
\text { (resina) }\end{array}$ & M.O. & $\underset{\mathrm{CaCl}_{2}}{\mathrm{pH}}$ & $\mathrm{K}$ & $\mathrm{Ca}$ & $\mathrm{Mg}$ & $\mathrm{H}+\mathrm{Al}$ & SB & CTC & V & $\mathrm{Cu}$ & $\mathrm{Fe}$ & $\mathrm{Mn}$ & $\mathrm{Zn}$ \\
\hline & $\left(\mathrm{mg} / \mathrm{dm}^{3}\right)$ & $\left(\mathrm{g} / \mathrm{dm}^{3}\right)$ & & -- & - & $(\mathrm{mm}$ & $\left.l_{c} / d^{3}\right)$ & - & ---- & $(\%)$ & ---- & $--(m$ & $\left./ \mathrm{dm}^{3}\right)$ & 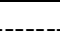 \\
\hline Arenosa & 7 & 26 & 4,6 & 1,6 & 9 & 4 & 38 & 15 & 53 & 28 & 0,6 & 63 & 11 & 0,4 \\
\hline Média & 7 & 23 & 3,9 & 1,0 & 3 & 1 & 72 & 5 & 77 & 6 & 0,7 & 95 & 3 & 0,6 \\
\hline Argilosa & 9 & 40 & 4,6 & 3,0 & 21 & 6 & 58 & 30 & 88 & 34 & 8,0 & 24 & 51 & 0,4 \\
\hline
\end{tabular}




\section{RESULTADOS E DISCUSSÃO}

Os resultados das análises químicas das amostras dos solos coletadas após incubação com carbonatos e adubo fosfatado estão apresentados na Tabela 3. Nos solos arenoso e de textura média os índices de saturação por bases ficaram próximos ao desejado. No solo argiloso, esse índice ficou cerca de $20 \%$ abaixo do que se pretendia, o que pode estar relacionado a uma menor eficiência da solução SMP em extrair a acidez potencial de solo mais argiloso e rico em matéria orgânica, com maior grau de tamponamento.

Nos solos arenoso e de textura média, os teores de $\mathrm{P}$ obtidos estavam dentro das classes muito baixo $\left(\mathrm{P}_{0}\right)$, médio $\left(\mathrm{P}_{1}\right)$, alto $\left(\mathrm{P}_{2}\right.$ e $\left.\mathrm{P}_{3}\right)$ e muito alto $\left(\mathrm{P}_{4}\right)$, considerando as classes de fertilidade de culturas perenes apresentadas em Raij et al. (1996). No solo de textura argilosa, os teores obtidos foram baixos no tratamento $\mathrm{P}_{0}$; médios, no tratamento $\mathrm{P}_{1}$; e altos, em $\mathrm{P}_{2}, \mathrm{P}_{3}$ e $\mathrm{P}_{4}$. A diferença nos teores de $\mathrm{P}$ disponível reflete a capacidade de retenção de fosfato dos solos, com o argiloso retendo mais do que o de textura média, e este, mais do que o arenoso.
Na Tabela 4 estão apresentadas as produções médias de matéria seca obtidas no primeiro e no segundo corte, e o total, além das produções relativas. Verifica-se que houve efeito significativo quanto a solo e doses de $\mathrm{P}$, e que o efeito da dose de $\mathrm{P}$ dependeu do solo. Houve aumento de produção com a aplicação de $\mathrm{P}$, e o maior acréscimo foi observado da dose zero para a dose $35 \mathrm{mg} / \mathrm{dm}^{3}$ nos três solos. Costa et al. (1983) também observaram que o maior incremento na produção de capim-colonião ocorreu no intervalo da dose zero para a primeira dose aplicada, que no caso foi $50 \mathrm{mg} / \mathrm{dm}^{3}$ de P, o que está de acordo com a lei dos incrementos decrescentes.

Determinou-se a curva de resposta de produção de matéria seca do capim em função do teor de $\mathrm{P}$ de cada solo nos dois cortes e total e as equações estão apresentadas na Tabela 5. Em todos os casos a equação de segundo grau propiciou o melhor ajuste, e todos os valores de $\mathrm{R}^{2}$ foram altos e significativos.

Na Tabela 6 estão apresentadas as médias dos teores de $\mathrm{P}$ e a quantidade absorvida pelas plantas. $\mathrm{O}$ teor de $\mathrm{P}$ na planta no primeiro corte foi afetado de forma significativa pelo solo e pela interação solo $\mathrm{x}$

TABELA 3. Resultados das análises químicas das amostras dos solos coletadas após incubação com carbonatos e fósforo ${ }^{1}$.

\begin{tabular}{|c|c|c|c|c|c|c|c|c|c|c|}
\hline $\begin{array}{l}\text { Dose de P } \\
\left(\mathrm{mg} / \mathrm{dm}^{3}\right)\end{array}$ & $\begin{array}{l}\mathrm{P}(\text { resina }) \\
\left(\mathrm{mg} / \mathrm{dm}^{3}\right)\end{array}$ & $\begin{array}{c}\text { M.O. } \\
\left(\mathrm{g} / \mathrm{dm}^{3}\right)\end{array}$ & $\begin{array}{c}\mathrm{pH} \\
\mathrm{CaCl}_{2}\end{array}$ & $\mathrm{~K}$ & $\mathrm{Ca}$ & $\begin{array}{l}\mathrm{Mg} \\
-(\mathrm{m} \\
\end{array}$ & $\begin{array}{l}\mathrm{H}+\mathrm{Al} \\
\left(\mathrm{dm}^{3}\right)\end{array}$ & SB & CTC & $\begin{array}{l}\mathrm{V} \\
(\%)\end{array}$ \\
\hline & \multicolumn{10}{|c|}{ Solo arenoso } \\
\hline 0 & 4 & 28 & 5,6 & 4,5 & 29 & 8 & 20 & 41 & 61 & 67 \\
\hline 35 & 21 & 27 & 5,6 & 4,4 & 30 & 9 & 22 & 43 & 65 & 66 \\
\hline 70 & 36 & 26 & 5,5 & 4,4 & 29 & 8 & 23 & 41 & 64 & 64 \\
\hline 105 & 58 & 27 & 5,5 & 4,5 & 29 & 8 & 24 & 41 & 65 & 64 \\
\hline \multirow[t]{2}{*}{140} & 71 & 27 & 5,4 & 4,4 & 30 & 8 & 25 & 43 & 68 & 63 \\
\hline & \multicolumn{10}{|c|}{ Solo de textura média } \\
\hline 0 & 4 & 23 & 5,5 & 3,7 & 38 & 8 & 23 & 49 & 72 & 68 \\
\hline 35 & 19 & 24 & 5,5 & 3,7 & 37 & 8 & 25 & 48 & 73 & 66 \\
\hline 70 & 34 & 21 & 5,4 & 3,7 & 37 & 8 & 26 & 48 & 74 & 65 \\
\hline 105 & 54 & 23 & 5,4 & 3,8 & 39 & 8 & 27 & 51 & 77 & 65 \\
\hline \multirow[t]{2}{*}{140} & 64 & 24 & 5,3 & 3,7 & 38 & 8 & 27 & 50 & 77 & 65 \\
\hline & \multicolumn{10}{|c|}{ Solo argiloso } \\
\hline 0 & 6 & 40 & 5,1 & 4,4 & 32 & 11 & 47 & 47 & 92 & 51 \\
\hline 35 & 19 & 41 & 5,1 & 4,9 & 31 & 12 & 46 & 48 & 94 & 52 \\
\hline 70 & 32 & 41 & 5,1 & 5,0 & 33 & 12 & 46 & 50 & 97 & 52 \\
\hline 105 & 46 & 40 & 5,0 & 5,0 & 33 & 12 & 47 & 50 & 97 & 52 \\
\hline 140 & 58 & 41 & 5,0 & 4,9 & 32 & 12 & 47 & 48 & 95 & 51 \\
\hline
\end{tabular}

${ }^{1}$ Médias de quatro repetições. 
dose de $\mathrm{P}$, mas não pela dose de $\mathrm{P}$. No segundo corte, houve efeito significativo dos dois fatores (solo e dose de P) e da interação.

Os teores de P na planta obtidos no primeiro corte nos solos de textura arenosa e argilosa estão den- tro da faixa adequada, sugerida por Werner et al. (1996); e no solo de textura média, estes valores só se apresentaram adequados nos tratamentos sem $\mathrm{Pe}$ com aplicação de $35 \mathrm{mg} / \mathrm{dm}^{3}$ de P. Como neste solo as plantas apresentaram maior crescimento, com

TABELA 4. Produção média e relativa de matéria seca do capim-tanzânia obtida no 1o e 2o corte e na soma dos dois cortes, em razão de doses de fósforo ${ }^{1}$.

\begin{tabular}{|c|c|c|c|c|c|c|}
\hline \multirow{2}{*}{$\begin{array}{l}\text { Dose de P } \\
\left(\mathrm{mg} / \mathrm{dm}^{3}\right)\end{array}$} & \multicolumn{2}{|c|}{$1^{\underline{\mathrm{O}}}$ corte } & \multicolumn{2}{|c|}{$2^{\circ}$ corte } & \multicolumn{2}{|c|}{ Total } \\
\hline & (g/vaso) & $(\%)$ & (g/vaso) & $(\%)$ & (g/vaso) & $(\%)$ \\
\hline & \multicolumn{6}{|c|}{ Solo arenoso } \\
\hline 0 & 0,95 & 1 & 4,88 & 6 & 5,83 & 4 \\
\hline 35 & 47,68 & 55 & 49,65 & 64 & 97,33 & 60 \\
\hline 70 & 67,43 & 78 & 58,15 & 76 & 125,58 & 77 \\
\hline 105 & 81,63 & 94 & 74,13 & 96 & 155,75 & 95 \\
\hline \multirow[t]{2}{*}{140} & 86,55 & 100 & 76,98 & 100 & 163,53 & 100 \\
\hline & \multicolumn{6}{|c|}{ Solo textura média } \\
\hline 0 & 2,13 & 2 & 6,60 & 6 & 8,73 & 4 \\
\hline 35 & 38,33 & 29 & 43,25 & 42 & 81,58 & 35 \\
\hline 70 & 78,95 & 60 & 67,90 & 65 & 146,85 & 62 \\
\hline 105 & 112,60 & 86 & 96,43 & 93 & 209,03 & 89 \\
\hline \multirow[t]{2}{*}{140} & 131,40 & 100 & 104,20 & 100 & 235,60 & 100 \\
\hline & \multicolumn{6}{|c|}{ Solo argiloso } \\
\hline 0 & 6,43 & 8 & 8,03 & 10 & 14,45 & 9 \\
\hline 35 & 45,88 & 55 & 48,53 & 63 & 94,40 & 59 \\
\hline 70 & 63,33 & 76 & 58,40 & 75 & 121,80 & 76 \\
\hline 105 & 77,35 & 93 & 73,18 & 95 & 150,53 & 94 \\
\hline 140 & 83,18 & 100 & 77,38 & 100 & 160,55 & 100 \\
\hline Solo & $60,8 * *$ & & $34,8^{* *}$ & & $97,8^{* *}$ & \\
\hline Dose de P & $602,1 * *$ & & $556,4 * *$ & & $1185,9^{* *}$ & \\
\hline Interação solo $\mathrm{x}$ dose de $\mathrm{P}$ & $28,8 * *$ & & $12,1 * *$ & & $36,6^{* *}$ & \\
\hline Coeficiente de variação (\%) & 9,0 & & 8,3 & & 6,1 & \\
\hline
\end{tabular}

TABELA 5. Equações de regressão para a produção de matéria seca (Y, g/vaso) do capim-tanzânia cultivado em solos com diferentes texturas, em razão de doses de fósforo $(\mathbf{x})$.

\begin{tabular}{|c|c|c|c|}
\hline Solo & Corte & Equação & $\mathrm{R}^{2}$ \\
\hline Arenoso & $\begin{array}{l}1^{\underline{o}} \text { corte } \\
2^{\underline{o}} \text { corte } \\
\text { Total }\end{array}$ & $\begin{array}{l}Y=-0,0237 x^{2}+2,9931 x-8,7631 \\
Y=-0,0202 x^{2}+2,5204 x-1,9457 \\
Y=-0,0439 x^{2}+5,5133 x-10,707\end{array}$ & $\begin{array}{l}0,992 * * \\
0,972 * * \\
0,986 * *\end{array}$ \\
\hline Textura média & $\begin{array}{l}1^{\underline{o}} \text { corte } \\
2^{\underline{o}} \text { corte } \\
\text { Total }\end{array}$ & $\begin{array}{l}Y=-0,0109 x^{2}+2,8986 x-10,088 \\
Y=-0,0152 x^{2}+2,6556 x-3,2691 \\
Y=-0,0261 x^{2}+5,5542 x-13,357\end{array}$ & $\begin{array}{l}0,998 * * \\
0,999 * * \\
0,999 * *\end{array}$ \\
\hline Argiloso & $\begin{array}{l}1^{\underline{o}} \text { corte } \\
2^{\underline{o}} \text { corte } \\
\text { Total }\end{array}$ & $\begin{array}{l}Y=-0,0297 x^{2}+3,3199 x-10,631 \\
Y=-0,0285 x^{2}+3,0760 x-6,6076 \\
Y=-0,0583 x^{2}+6,4007 x-17,283\end{array}$ & $\begin{array}{l}0,992 * * \\
0,974 * * \\
0,986 * *\end{array}$ \\
\hline
\end{tabular}

** Significativo a $1 \%$ de probabilidade pelo teste $\mathrm{t}$. 
maior produção de matéria seca, há indicativo de que ocorreu o efeito de diluição descrito por Costa et al. (1983). Valores maiores foram relatados por Corrêa et al. (1996).

$\mathrm{O}$ teor de $\mathrm{P}$ na planta encontrado no primeiro corte foi maior do que no segundo. Esta variação é causada pela maior proporção de folhas do que de colmos no primeiro corte do que no segundo. No primeiro corte, as plantas foram cortadas a $10 \mathrm{~cm}$ do solo e, no segundo corte, além de serem cortadas rente ao solo, algumas plantas já apresentavam inflorescências, o que ajudou a aumentar a proporção de colmos.

Apesar dos comentários apresentados, a validade de dados de teor de P na planta é restrita em experimentos desse tipo. Pode-se observar que plantas que não cresceram por deficiência de $\mathrm{P}$ apresentavam, aparentemente, teor adequado, e nas plantas que cresceram mais, pelo maior teor de $\mathrm{P}$ no solo, o teor encontrava-se abaixo do adequado. Essa discrepância não recomenda análises estatísticas mais detalhadas desses dados. Quanto a quantidade de P absorvida, houve efeito significativo do solo, de doses de $\mathrm{P}$ e da interação entre os dois fatores, exceto para o segundo corte, em que não se verificou efeito da interação. No segundo corte, a quantidade absorvida foi menor, em virtude de menor concentração do elemento na matéria seca e também de menor produção vegetal. Na Tabela 7 estão apresentadas as equações de segundo grau ajustadas aos dados de teor de $\mathrm{P}$ no solo x quantidade de $\mathrm{P}$ absorvida pelo capim. Observa-se a mesma tendência determinada para matéria seca (Tabela 5), com valores de $\mathrm{R}^{2}$ significativos e altos.

Relacionando os dados de análise de solo para $\mathrm{P}$ com as respectivas produções relativas (Tabelas $3 \mathrm{e}$ 4), determinou-se o nível crítico geral dos três solos, segundo o método gráfico de Cate Junior \& Nelson (1965), e o resultado está apresentado na Fig. 1. No caso, o nível crítico determinado para $80 \%$ da produção máxima de matéria seca foi $38 \mathrm{mg} / \mathrm{dm}^{3}$.

TABELA 6. Valores médios do teor de $P$ nas plantas e da quantidade de fósforo absorvida ${ }^{1}$.

\begin{tabular}{|c|c|c|c|c|c|c|}
\hline \multirow[t]{2}{*}{ Solo } & \multirow{2}{*}{$\begin{array}{l}\text { Dose de P } \\
\left(\mathrm{mg} / \mathrm{dm}^{3}\right)\end{array}$} & \multicolumn{2}{|c|}{ Teor de $\mathrm{P}$} & \multicolumn{3}{|c|}{ Quantidade absorvida de P } \\
\hline & & $1^{\mathrm{o}}$ corte & $2^{\underline{o}}$ corte & $1^{\mathrm{o}}$ corte & $2^{\underline{o}}$ corte & Total \\
\hline & & ----------- & ) --------- & ----------- & (mg/vaso) & --------- \\
\hline \multirow[t]{5}{*}{ Arenoso } & 0 & 0,95 & 0,84 & 1 & 4 & 5 \\
\hline & 35 & 1,05 & 0,84 & 50 & 42 & 92 \\
\hline & 70 & 0,96 & 0,92 & 65 & 53 & 118 \\
\hline & 105 & 1,17 & 1,03 & 96 & 76 & 172 \\
\hline & 140 & 1,21 & 1,00 & 105 & 77 & 182 \\
\hline \multirow[t]{5}{*}{ Textura média } & 0 & 1,18 & 0,98 & 2 & 6 & 9 \\
\hline & 35 & 1,02 & 0,86 & 39 & 37 & 76 \\
\hline & 70 & 0,80 & 0,79 & 63 & 54 & 116 \\
\hline & 105 & 0,86 & 0,78 & 96 & 75 & 171 \\
\hline & 140 & 0,95 & 0,79 & 125 & 83 & 207 \\
\hline \multirow[t]{5}{*}{ Argiloso } & 0 & 1,17 & 0,84 & 8 & 7 & 14 \\
\hline & 35 & 1,12 & 0,84 & 52 & 41 & 93 \\
\hline & 70 & 1,36 & 1,14 & 86 & 66 & 153 \\
\hline & 105 & 1,25 & 1,06 & 97 & 78 & 175 \\
\hline & 140 & 1,39 & 1,17 & 117 & 90 & 206 \\
\hline \multicolumn{2}{|l|}{ Solo } & $32,8 * *$ & $18,7 * *$ & $3,8 *$ & $5,0 *$ & $6,3 * *$ \\
\hline \multicolumn{2}{|l|}{ Dose de $\mathrm{P}$} & $2,5^{\mathrm{NS}}$ & $5,1 * *$ & $227,7 * *$ & $268,7 * *$ & $362,4 * *$ \\
\hline \multicolumn{2}{|c|}{ Interação solo $\mathrm{x}$ dose de $\mathrm{P}$} & $5,9 * *$ & $8,3^{* *}$ & $2,2 *$ & $1,4^{\mathrm{NS}}$ & $2,3 *$ \\
\hline \multicolumn{2}{|c|}{ Coeficiente de variação $(\%)$} & 10,8 & 9,4 & 15,0 & 12,5 & 11,4 \\
\hline
\end{tabular}

${ }^{1}$ Médias de quatro repetições.

NS,$*$ e ** Não-significativo e significativo a $5 \%$ e $1 \%$ de probabilidade, respectivamente, pelo teste $\mathrm{F}$. 
TABELA 7. Equações de regressão para a quantidade de fósforo absorvido (Y) pelo capim-tanzânia, cultivado em solos com texturas diferentes, em razão de doses de fósforo $(x)$.

\begin{tabular}{|c|c|c|c|}
\hline Solo & Corte & Equação & $\mathrm{R}^{2}$ \\
\hline Arenoso & $\begin{array}{l}1^{\underline{0}} \text { corte } \\
2^{\underline{0}} \text { corte } \\
\text { Total }\end{array}$ & $\begin{array}{l}Y=-0,0166 x^{2}+2,7459 x-7,2689 \\
Y=-0,0159 x^{2}+2,2650 x-3,3318 \\
Y=-0,0325 x^{2}+5,0109 x-10,601\end{array}$ & $\begin{array}{l}0,983 * * \\
0,986^{* *} \\
0,988^{* *}\end{array}$ \\
\hline Textura média & $\begin{array}{l}1^{\underline{o}} \text { corte } \\
2^{\underline{0}} \text { corte } \\
\text { Total }\end{array}$ & $\begin{array}{l}Y=-0,0006 x^{2}+1,9868 x-3,4305 \\
Y=-0,0122 x^{2}+2,0821 x-0,9809 \\
Y=-0,0120 x^{2}+3,9877 x-3,1779\end{array}$ & $\begin{array}{l}0,991 * * \\
0,997 * * \\
0,995 * *\end{array}$ \\
\hline Argiloso & $\begin{array}{l}1^{\circ} \text { corte } \\
2^{\underline{o}} \text { corte } \\
\text { Total }\end{array}$ & $\begin{array}{l}Y=-0,0300 x^{2}+3,9286 x-13,117 \\
Y=-0,0239 x^{2}+3,0844 x-9,8831 \\
Y=-0,0565 x^{2}+7,1784 x-24,968\end{array}$ & $\begin{array}{l}0,989 * * \\
0,996 * * \\
0,992 * *\end{array}$ \\
\hline
\end{tabular}

** Significativo a $1 \%$ de probabilidade pelo teste $\mathrm{t}$.

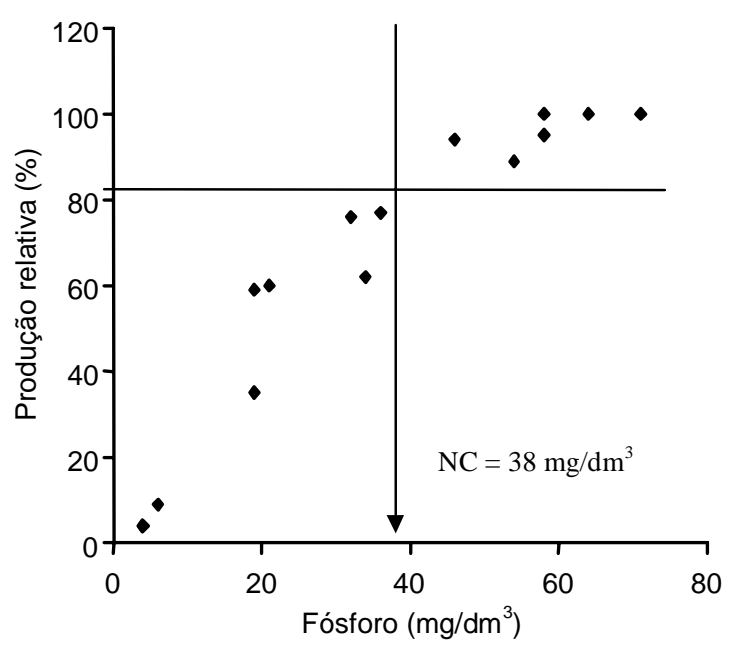

FIG. 1. Nível crítico de fósforo no solo para o capimtanzânia.

Corrêa et al. (1996) obtiveram $21 \mathrm{mg} / \mathrm{dm}^{3}$ especificamente para capim-tanzânia. Em ambos os casos o extrator era a resina, e o nível crítico foi determinado para $80 \%$ da produção máxima.

Variações nos valores obtidos para níveis críticos são esperadas e, de acordo com Bates (1971), devem-se a fatores como: espécie, condições ambientais, forma disponível do nutriente em estudo, e disponibilidade dos demais, entre outros. No presente trabalho, não foi observada variação no nível crítico quando se fez o cálculo para o primeiro, para o segundo e para a soma dos dois cortes, mas no trabalho de Fonseca et al. (1988) ficou clara a variação causada pela diferença entre espécies e pela idade da planta. Recentemente, Santos et al. (1998) determinaram o nível crítico para $P$. maximum cv. Mombaça e $B$. decumbens cv. Basilisk em razão da idade. Os níveis críticos (extrator Mehlich 1), considerando-se as avaliações dos 14 aos 70 dias, decresceram de 70,1 para $21,4 \mathrm{mg} / \mathrm{dm}^{3}$ em braquiária, e de 54,5 para $18,4 \mathrm{mg} / \mathrm{dm}^{3}$ em capim-mombaça. Como a braquiária é considerada menos exigente, os autores atribuíram o resultado à limitação de crescimento do capim-mombaça provocado por quantidades insuficientes de $\mathrm{N}$ e $\mathrm{K}$.

Considerando as doses de N, K e de outros nutrientes que foram aplicadas, e a produção de matéria seca obtida, que está acima das relatadas em outros experimentos do mesmo tipo, pode-se admitir que não houve limitação de crescimento do capimtanzânia por deficiência nutricional, e isto justificaria o nível crítico determinado estar acima dos já relatados na literatura. Em apoio a esta expectativa está o fato de haver concordância muito boa entre o valor obtido e a citação de Werner et al. (1996), para os quais não é necessário aplicar P para instalação de pastagens com capins exigentes quando o teor no solo for maior do que $40 \mathrm{mg} / \mathrm{dm}^{3}$ (resina).

\section{CONCLUSÕES}

1. Com a aplicação de até $35 \mathrm{mg} / \mathrm{dm}^{3}$ de P, é obtido o maior incremento na produção de matéria seca do capim-tanzânia, independentemente da textura do solo.

2. O nível crítico de P no solo determinado para $80 \%$ da produção máxima de matéria seca do capimtanzânia é $38 \mathrm{mg} / \mathrm{dm}^{3}$. 


\section{REFERÊNCIAS}

BATAGLIA, O.C.; FURLANI, A.M.C.; TEIXEIRA, J.P.F.; FURLANI, P.R.; GALLO, J.R. Métodos de análise química de plantas. Campinas : Instituto Agronômico, 1983. 48p. (Boletim técnico, 78).

BATES, T.E. Factors affecting critical nutrient concentrations in plants and their evaluation: a review. Soil Science, Baltimore, v.112, p.116-130, 1971.

CAMARGO, O.A.; MONIZ, A.C.; JORGE, J.A.; VALADARES, J.M.A.S. Métodos de análise química, mineralógica e física de solos do Instituto Agronômico de Campinas. Campinas : Instituto Agronômico, 1986. 94p. (IAC. Boletim Técnico, 106).

CATE JUNIOR, R.B.; NELSON, L.A. A rapid method for correlation of soil test analysis with plant response data. Raleigh : International Soil Testing, 1965. 24p. (Technical Bulletin, 1).

CORRÊA, L.A.; FREITAS, A.R.; EUCLIDES, V.P.B. Níveis críticos de fósforo para o estabelecimento de quatro cultivares de Panicum maximum em Latossolo Vermelho-Amarelo, álico. In: REUNIÃO ANUAL DA SOCIEDADE BRASILEIRA DE ZOOTECNIA, 33., 1996, Fortaleza. Anais. Fortaleza : Sociedade Brasileira de Zootecnia, 1996. p.169-170.

CORRÊA, L.A.; FREITAS, A.R.; VITTI, G.C. Respostas de Panicum maximum cv. Tanzânia a fontes e doses de fósforo no estabelecimento. In: REUNIÃO ANUAL DA SOCIEDADE BRASILEIRA DE ZOOTECNIA, 34., 1997, Juiz de Fora. Anais. Juiz de Fora : Sociedade Brasileira de Zootecnia, 1997. p.190-192.

COSTA, G.C.; MONERATT, P.H.; GOMIDE, J.A. Efeito de doses de fósforo sobre o crescimento e o teor de fósforo de capim-jaraguá e capim-colonião. Revista da Sociedade Brasileira de Zootecnia, Viçosa, v.12, p.1-10, 1983.

EUCLIDES, V.P.B. Algumas considerações sobre manejos de pastagens. Campo Grande : EmbrapaCNPGC, 1994. 31p. (Embrapa-CNPGC. Documentos, 57).

EUCLIDES, V.P.B. Utilización de pasturas tropicales para producción de carne. In: CONGRESSO INTERNACIONAL DE TRANSFERENCIA TECNOLÓGICA AGROPECUARIA, 3., 1996, Mariano Roque Alonso. Anais. Mariano Roque Alonso : Consorcio de Ganaderos para Experimentación Agropecuária, 1996. p.41-60.

FONSECA, D.M.; ALVAREZ VENEGAS, V.H.; NEVES, J.C.L.; GOMIDE, J.A.; NOVAIS, R.F.; BARROS,
N.F. Níveis críticos de fósforo em amostras de solos para o estabelecimento de Andropogon gayanus, Brachiaria decumbens e Hyparrhenia rufa. Revista Brasileira de Ciência do Solo, Campinas, v.12, p.4958,1988

RAIJ, B. van; CANTARELLA, H.; QUAGGIO, J.A.; FURLANI, A.M.C. (Ed.). Recomendações de adubação e calagem para o Estado de São Paulo. 2.ed. Campinas : Instituto Agronômico, 1996. 285p. (IAC. Boletim técnico, 100).

RAIJ, B. van; QUAGGIO, J.A.; CANTARELLA, H.; FERREIRA, M.E.; LOPES, A.S.; BATAGLIA, O.C. Análise química do solo para fins de fertilidade. Campinas : Fundação Cargill, 1987. 170p.

REGO, M.C.; GOMIDE, J.A.; NOVAIS, R.F. Phosphorus requirements for grass establishment in five tropical soils. In: INTERNATIONAL GRASSLAND CONGRESS, 15., 1985, Kyoto. Proceedings. Kyoto : Science Council of Japan/Japanese Society of Grassland Science, 1985. p.476-477.

SANTOS, H.Q.; FONSECA, D.M.; CANTARUTTI, R.B.; NOBREGA, E.B.; PEREIRA, A.L. Níveis críticos de fósforo para gramíneas forrageiras, em função da idade das plantas. In: REUNIÃO ANUAL DA SOCIEDADE BRASILEIRA DE ZOOTECNIA, 35. 1998, Botucatu. Anais. Botucatu : Sociedade Brasileira de Zootecnia, 1998. p.260-262.

SENGIK, E.; MACHADO, A.O.; CECATO, U.; PINTRO, J.C.; PEREIRA, L.A.F. Efeito de diferentes valores por saturação de bases da terra na produção de matéria seca do capim-tanzânia (Panicum maximum Jacq. cv. Tanzânia) e do milho (Zea mays L.). Revista UNIMAR, Maringá, v.18, p.505-512, 1996a.

SENGIK, E.; MACHADO, A.O.; CECATO, U.; PINTRO, J.C.; PEREIRA, L.A.F.; MUNIZ, A.S. Efeito da adubação por subtração de nutrientes na produção de massa seca do milho (Zea mays L.) e do capimtanzânia (Panicum maximum Jacq. cv. Tanzânia) em terra ácida. Revista UNIMAR, Maringá, v.18, p.513521, 1996b.

VIEIRA, J.M. Qual a melhor forrageira? Características de adaptação agronômica de espécies e cultivares de forrageiras tropicais. In: EMBRAPA. Centro Nacional de Pesquisa de Gado de Corte (Campo Grande, MS). Curso de pastagens para sementeiros. Campo Grande, 1993. p.5-12.

WERNER, J.C.; PAULINO, V.T.; CANTARELLA, H.; ANDRADE, N.O.; QUAGGIO, J.A. Forrageiras. In: RAIJ, B. van; CANTARELLA, H.; QUAGGIO, J.A.; FURLANI, A.M.C. (Ed.). Recomendações de adubação e calagem para o Estado de São Paulo. Campinas : Instituto Agronômico, 1996. p.263-273. (IAC. Boletim Técnico, 100). 